\title{
Habitual self-regulatory orientation and ease-of-retrieval: Regulatory focus qualifies the impact of subjective experiences in judgment
}

\author{
Rainer Greifeneder · Johannes Keller
}

Published online: 30 October 2011

(C) Springer Science+Business Media, LLC 2011

\begin{abstract}
Eager strategies of self-regulation, known as promotion orientation, and cautious or vigilant strategies of self-regulation, known as prevention orientation, have been found to be associated with distinct patterns of goal attainment and information exploration. Building on these findings, we hypothesize that self-regulation in a promotion versus prevention focus triggers specific patterns of information use in judgment. Specifically, we predict that reliance on ease-of-retrieval-the feeling of ease or difficulty associated with accessing information-is particularly pronounced with a predominant promotion- compared to prevention-orientation. Two experiments that manipulate ease-of-retrieval and assess habitual differences in regulatory focus orientation support this prediction. The current contribution thus extends previous research by documenting that habitual tendencies of promotion-oriented as compared to prevention-oriented self-regulation are associated with reliance on distinct information sources in judgment.
\end{abstract}

Keywords Regulatory focus - Promotion - Prevention . Ease-of-retrieval $\cdot$ Feelings $\cdot$ Judgment

R. Greifeneder $(\bowtie)$

School of Social Sciences, University of Mannheim,

A5, A434, 61831 Mannheim, Germany

e-mail: greifeneder@uni-mannheim.de

J. Keller

University of Ulm, Ulm, Germany

\section{Introduction}

Self-regulatory orientation fundamentally influences many social cognitive mechanisms and behavioral tendencies (see contributions in Baumeister and Vohs 2004). For instance, it has been observed that an eager style of selfregulation is positively linked to creative thinking, whereas a vigilant style is associated with more careful, analytic processing (Friedman and Förster 2001). Also, classic psychological phenomena, such as the endowment effect, have been shown to be affected by individuals' self-regulatory orientation (cf. Liberman et al. 1999). One particularly prominent perspective in this realm is regulatory focus theory (Higgins 1997). Regulatory focus theory differentiates between two modes of self-regulation known as promotion and prevention, which have been shown to be associated with distinct sets of needs, goals, and behavioral tendencies (for reviews, Higgins 1998; Higgins and Spiegel 2004), and with distinct preferences for information sources in judgment. For instance, when compared with prevention-oriented participants, promotion-oriented participants have been shown (a) to rely more on an advertisement's affective tone than on its content (Pham and Avnet 2004), (b) to rely more on affective feelings than on cognitive assessments (Pham and Avnet 2009), and (c) to rely more on internal cues such as implicit preferences (Evans and Petty 2003; Florack et al. 2010). Little is known, however, about the interplay of promotion and prevention and the use of so-called cognitive feelings in judgment, that is, experiences associated with mental processing (e.g., Alter and Oppenheimer 2009). The current contribution approaches this question by focusing on feelings of ease or difficulty associated with recalling instances from memory, so-called ease-of-retrieval experiences (Schwarz et al. 1991). Although this may not seem 
intuitive at first glance, ease-of-retrieval experiences have been documented as important sources of information in judgment and decision making upon which individuals frequently draw (e.g., Greifeneder et al. 2011a; Schwarz et al. 2008). Building on previous evidence and on the idea that different types of information are considered particularly relevant by individuals in a promotion versus a prevention focus, we hypothesize that reliance on ease-ofretrieval is more pronounced for individuals characterized by a predominant promotion orientation as compared to individuals with a predominant prevention orientation. This interaction hypothesis is tested in two studies that employ different measures of habitual self-regulatory orientation. To substantiate this hypothesis, we discuss the relevant literature, beginning with ease-of-retrieval.

\section{Reliance on ease-of-retrieval in judgment}

Classic models of judgment and decision making have focused predominantly on content as the primary source of information, that is, descriptive features pertaining to the evaluation target. Research over the last three decades, however, has challenged this perspective by demonstrating that judgments and decisions may be formed not only on the basis of content, but also on the basis of feelings (e.g., Schwarz and Clore 2007). For instance, it has been shown that individuals perceive themselves as more assertive when the recall of pertinent instances feels easy rather than difficult (Schwarz et al. 1991). Current theorizing across the various social sciences therefore conceptualizes judgment and decision making as a function of both content information and feelings (e.g., Alter and Oppenheimer 2009; Schwarz and Clore 2007). In this vein, the present contribution focuses on the juxtaposition of content versus the felt ease or difficulty with which information can be accessed (generically referred to as "ease-of-retrieval" or "accessibility experiences," Schwarz 1998, 2004).

Research on ease-of-retrieval initially was focused on frequency judgments, demonstrating that the more easily pertinent instances can be retrieved from memory, the more numerous an object is judged to be (Tversky and Kahneman 1973; see also Aarts and Dijksterhuis 1999). Subsequent research has revealed that accessibility experiences influence judgments and decisions in many other domains. For instance, judgments about the self (e.g., Schwarz et al. 1991; see also Greifeneder and Bless 2008) and others (e.g., Dijksterhuis et al. 1999; Haddock 2002) are more positive when positively valued self- or otherrelevant information can be easily retrieved. Similarly, evaluations of objects and products are influenced by the ease or difficulty with which relevant pieces of information can be brought to mind (e.g., Florack and Zoabi 2003; Wänke et al. 1997). Moreover, concepts such as attitude strength (Haddock et al. 1999), memory performance (e.g., Winkielman et al. 1998), and fairness considerations (Greifeneder et al. 2011b; Janssen et al. 2011) are informed by ease-of-retrieval. This short list of pertinent findings (for reviews see Schwarz 2004; Schwarz and Clore 2007) clearly shows that judgments can be influenced by ease-ofretrieval. Models conceptualizing this influence generally assume that ease-of-retrieval feelings enter the judgment process directly as a source of information (e.g., Schwarz et al. 1991) which is seen as independent of content information (rather than being mediated through content). This perspective parallels the theoretical position of feelings-as-information in the literature on affective feelings (e.g., Clore et al. 2001).

In addition to demonstrating that ease-of-retrieval may influence judgment (in so called first generation research, Zanna and Fazio 1982), researchers have addressed the question of under which conditions ease-of-retrieval may be expected to influence judgments and decisions. This so called second or third generation research is of particular importance because knowing that an effect can occur does not provide much information about its ecological importance, since an effect observed in a particular investigation may still be unlikely to occur outside psychological laboratories. To address this question, a recent review identified five major categories of moderators which state that reliance on ease-of-retrieval in judgment likely occurs (a) when ease-of-retrieval feelings exceed a certain threshold of salience, (b) when feelings are perceived as representative of the evaluation target, (c) when feelings are perceived as relevant for the judgment, (d) when judgments are evaluatively malleable, and (e) when processing intensity is low (Greifeneder et al. 2011a). To the best of our knowledge, however, there is no evidence concerning whether promotion versus prevention triggers differential reliance on ease-of-retrieval and content, despite there being good reason to expect such an impact, as detailed below.

Although investigations often pointedly pit ease-ofretrieval against content, it is likely that both sources of information are used in judgment formation, though in varying degrees. Moderating variables presumably affect the degree of use, as opposed to creating an either-or situation. Consequently, when findings are said to reflect either ease-of-retrieval or content, they most likely portray a relative dominance of the one over the other, rather than a situation in which one alone was used and the other completely ignored. This does not limit the interpretability of such patterns of results, but cautions against a simplified black-white perspective that may not do justice to the way judgments and decisions are formed. With this in mind, we adopt the terminology of ease-of-retrieval versus content effects for theorizing and analysis. 
Regulatory-focus theory

Going beyond the basic hedonic principle that people approach pleasure and avoid pain, regulatory focus theory (RFT) differentiates distinct types of pleasure and pain which reflect the motivational underpinnings of two independent systems known as promotion focus and prevention focus (Higgins 1997, 1998). Self-regulation with a promotion focus originates in the motivation to attain growth and nurturance and is prevalent in the pursuit of ideals, dreams, and aspirations. It is characterized by approach-oriented goal strategies which are reflected in eagerness and a special sensitivity to the presence or absence of positive outcomes. In contrast, selfregulation with a prevention focus originates in the motivation to attain security and is prevalent in the pursuit of oughts, duties, and responsibilities. It is characterized by avoidanceoriented goal strategies which are reflected in vigilance and a special sensitivity to the presence or absence of negative outcomes (for reviews, Higgins 1998; Higgins and Spiegel 2004).

The eagerness associated with promotion-focused selfregulation and the vigilance or cautiousness associated with prevention-focused self-regulation fuel specific goal attainment and information exploration strategies. Promotion-focused individuals are characterized by a desire to reach gains and to avoid non-gains. This desire is reflected in a tendency to seize opportunities and a high degree of willingness to explore (new) alternatives. In contrast, prevention-focused individuals are characterized by a desire to avoid losses and to attain non-losses. This desire is reflected in a tendency to be cautious and vigilant. For instance, when confronted with a choice between the status quo and a new course of action, promotion-focused individuals tend to opt for the more explorative option ("seizing opportunities"), whereas prevention-focused individuals tend to choose the status quo ("being cautious", Liberman et al. 1999).

It should be noted that promotion and prevention are not conceptualized as two endpoints of a single continuum, but as independent self-regulation tendencies that may be simultaneously active (e.g., Molden et al. 2008). However, in a specific situation, or habitually for some individuals, one self-regulatory tendency may be more pronounced than the other. It is this relative dominance that is meant when denoting individuals or situations as (relatively) promotion-oriented or (relatively) prevention-oriented (Higgins et al. 2001).

Promotion, prevention, and the use of ease-of-retrieval versus content

Several lines of argument have suggested that the eager pursuit of opportunities associated with promotion focus and the vigilant insurance against mistakes associated with prevention focus produce different exploration strategies when forming judgments and decisions. Specifically, there is reason to assume that promotion-oriented self-regulation triggers a preference for ease-of-retrieval over content, whereas prevention-oriented self-regulation triggers a preference for content over ease-of-retrieval, as detailed in what follows.

First, the prevention-induced tendency to be cautious and risk-avoidant should trigger a preference for information that is perceived as reliable and trustworthy. When compared with ease-of-retrieval experiences, accessible content is likely to be seen as a more reliable information source, especially since feelings in general are often perceived as erroneous and misleading (Elster 1999). Prevention-focused individuals may, therefore, perceive accessible content as more diagnostic and relevant and thus prefer content over ease-of-retrieval experiences. In contrast, the promotion-induced tendency to be eager and to apply holistic (global) processing strategies (cf. Förster and Higgins 2005) may invite the consideration of information sources other than content, such as ease-of-retrieval. Because promotion-focused individuals are known to favor speed over accuracy (Förster et al. 2003), and because ease-of-retrieval experiences allow for particularly fast and efficient judgment formation (e.g., Greifeneder and Bless 2007), promotion-focused individuals may prefer ease-ofretrieval experiences over accessible content information.

Second, eagerness induced by promotion has been shown to foster reliance on heuristics, whereas vigilance induced by prevention has been shown to foster systematic processing (Friedman and Förster 2000). To the extent that reliance on ease-of-retrieval reflects heuristic processing as suggested from the beginning of research in this area (e.g., Tversky and Kahneman 1973)—whereas the integration of content information requires systematic processing, this line of reasoning equally supports the prediction that promotion fosters reliance on ease-ofretrieval, and prevention reliance on content information.

Finally, promotion-oriented regulation has been shown to be related to global or holistic processing, whereas prevention-oriented regulation is associated with local processing (Förster and Higgins 2005). Since cognitive feelings such as ease-of-retrieval are often characterized as global or meta-summaries of activated information and associated processes (Koriat and Levy-Sadot 1999), whereas content needs to be integrated, this perspective similarly supports the prediction that promotion is associated with reliance on ease-of-retrieval, whereas prevention is associated with the use of content.

To summarize, several lines of argument converge in suggesting that the two different regulatory strategies known as promotion and prevention are associated with reliance on 
distinct information sources in judgment. Building on this evidence, we hypothesize that reliance on ease-of-retrieval versus content is more pronounced with individuals characterized by a predominantly promotion-oriented as compared with a prevention-oriented self-regulation. To our knowledge, this hypothesis has not been investigated so far. It receives indirect support, however, from two sets of conceptually related findings. First, Pham and Avnet (2004, 2009) have demonstrated that promotion-oriented self-regulation triggers feeling-based judgment formation, whereas prevention-oriented self-regulation triggers systematic content integration. Presumably this is because prevention-oriented individuals perceive affective information as less diagnostic or relevant than do promotion-oriented individuals. To the extent that affective and cognitive feelings are part of the same unity (e.g., Clore 1992), these findings from the domain of affective feelings conceptually sustain the hypothesis being investigated. Second, Florack et al. (2010) have reported that promotion-focused individuals are more likely to rely on implicit preferences in consumption choices than are preventionfocused individuals. Because implicit preferences share many features with cognitive feelings-such as not being easily scrutinized for validity, being continually available, and constituting internal rather than external cues - these findings may equally support the hypothesis that promotion versus prevention may be associated with differential reliance on accessible content and accessibility experiences in judgment.

It should be noted that the present hypothesis focuses on the moderating impact of regulatory focus on different kinds of information-accessible content versus accessibility experiences - in judgment. This focus needs to be differentiated from findings showing that fluency may play a critical mediating role in regulatory fit effects (Lee and Aaker 2004).

\section{Experiment 1}

Experiment 1 is intended to test whether habitual differences in regulatory orientation moderate reliance on ease-ofretrieval in judgment. Differences in habitual self-regulatory orientation were assessed with a measure developed by Lockwood et al. (2002; German version, Keller 2008). This measure was placed at the end of the experiment so that - at the time of judgment-habitual self-regulatory orientation could be expected to be no more salient than usual.

Experiences of ease or difficulty were induced by means of a task introduced by Schwarz et al. (1991). In this paradigm-henceforth referred to as ease-of-retrieval task-, participants are asked to recall different amounts of information, such as 2 (few) versus 6 (many) arguments in favor of extending the local city airport. Subsequently, participants are asked to form a related judgment, such as evaluating the airport extension. If individuals rely on easeof-retrieval, the recall of few examples, which is easy, should result in more positive evaluations than the recall of many examples, which is difficult. After all, if it is easy (difficult) to come up with arguments favoring the extension, chances are that one is (is not) supportive. Such a pattern of results is generally referred to as an ease-ofretrieval effect. Importantly, if individuals rely on content information, the recall of many (as opposed to few) examples will result in more favorable attitudes, because more supporting evidence would suggest a more favorable evaluation. Note that this content-based pattern is diametrically opposed to that obtained when individuals rely on ease-of-retrieval. Hence, by examining patterns of results obtained with the ease-of-retrieval task, conclusions can be drawn as to the conditions that moderate reliance on easeof-retrieval versus content in judgment (e.g., Schwarz 2004; for a discussion, see Greifeneder et al. 2011a).

Interestingly, previous research using the ease-of-retrieval task has reported ease-of-retrieval effects without referring to habitual differences in regulatory focus orientation (e.g., Schwarz et al. 1991). At first glance, such overall ease-ofretrieval effects appear to contradict the current hypothesis of a dispositional moderating variable. However, this contradiction is not genuine. First, for moderation to occur, it is sufficient that prevention-focused individuals rely relatively less on ease-of-retrieval and relatively more on content information. The overall ease-of-retrieval effect observed in earlier research may thus have disguised within-sample differences. This perspective suggests that research investigating the moderating impact of regulatory focus will likely expose significant ease-of-retrieval effects for promotion-focused individuals, but non-significant content effects for preventionfocused individuals. We therefore restrict statistical predictions to the hypothesized interaction effect. Second, investigations differ in their surrounding variables. By fine-tuning surrounding variables so that reliance on content becomes more likely than is usual-for example by increasing processing intensity (Florack and Zoabi 2003) - the general predominance of ease-of-retrieval over content may be shifted so that, on average, the pattern of results is not indicative of either source. We have capitalized on this consideration to increase the likelihood of detecting moderation. Note that such fine-tuning does not limit the interpretability of the reported findings, because what matters in moderation are relative differences.

Method

\section{Participants and design}

A total of 81 University of Mannheim students participated in return for 1 EUR and a popular chocolate treat (total 
about 2 USD at that time) in a study on "information processing." Participants were randomly assigned to one of two conditions of the ease-of-retrieval task. Four participants were excluded from further analyses because of missing values. Of the remaining participants, 43 were female, 34 were male, and the mean age was 22.04 years $(\mathrm{SD}=3.52)$.

\section{Procedure and materials}

Manipulation of ease-of-retrieval On the first page, participants read that we were interested in reasons supporting the extension of the Mannheim City Airport. To date, the airport is only used by small airplanes; a sizeable extension, however, could render the airport suitable for larger aircraft. Against the background of this information, participants were asked to write down either two (few) or six (many) arguments in favor of the airport extension. They were told that these arguments could be, for instance, from the position of those studying, working, or traveling. Moreover, abstract arguments-e.g., general economic welfare of the region-were also said to be suitable. Independent pre-testing with this set of instructions had shown that noting two as compared with six reasons is significantly easier, thus creating conditions of differential ease-of-retrieval (Schwarz et al. 1991). Note that the topic "airport extension" was explicitly chosen because having better air transportation is a topic likely to be of high relevance to students at a major university and business school. Based on earlier evidence (for a review, Greifeneder et al. 2011a), we speculated that this increase in the topic's relevance fosters processing intensity, which, in turn, should shift the balance from general reliance on ease-of-retrieval to a situation where content information is relied upon more than is usual.

Manipulation check ease-of-retrieval On the next page, participants were asked the following three questions: "How easy or difficult was it to list the reasons in favor of the airport extension?;" "How easy or difficult would it have been for you to list even more reasons?;" and "How easy or difficult was it to list the last reason?" Answers were given on 9-point rating scales from 1, very difficult, to 9, very easy.

Dependent variable On a new page, participants were asked to answer five questions with respect to the potential airport extension. The first two items read: "I evaluate the extension of the city airport as ..." (1, rather negative, 9 , rather positive); "I consider the extension of the city airport to be ..." (1, very bad, 9, very good). All five evaluation items were rated on 9-point Likert scales, with varying anchors.
Habitual regulatory orientation Finally, habitual regulatory focus orientation was assessed by means of six items from the measure developed by Lockwood et al. (2002). ${ }^{1}$ Three items targeted promotion focus (Cronbach's $\alpha=.65$ ); three items targeted prevention focus (Cronbach's $\alpha=.70$ ); all items were scaled from 1 , does not apply, to 9, strongly applies. Following previous research, relative focus orientation was computed by separately averaging promotion items and prevention items and then subtracting the promotion from the prevention average. In the current experiment, the overall mean is -1.79 $(\mathrm{SD}=1.63)$. Using difference scores is common practice in self-regulation research and reflects a particular interest in the influence of individuals' predominant regulatory orientation (e.g., Cesario et al. 2004; Higgins et al. 2001; Molden and Higgins 2008). We refer to this difference measure as regulatory orientation below.

Results

\section{Preliminary analyses}

Regulatory focus orientation was assessed at the end of the experiment so as to prevent heightened salience of regulatory concerns. A downside of that proceeding, however, is the possibility that the independent variable, number of arguments, might have differentially affected the assessment of the continuous moderator, habitual regulatory orientation. To address this concern, regulatory orientation was submitted to a t-test for independent groups (few vs. many arguments). This analysis yielded no meaningful difference, $t<.22$, suggesting that the assessment of dispositional regulatory orientation was unaffected by the situational manipulation of ease-of-retrieval.

To test for the success of the ease-of-retrieval manipulation, the three items targeting perceived ease or difficulty were averaged (Cronbach's $\alpha=.90$ ) and entered as the dependent variable in a hierarchical regression analysis. Number of arguments (few $=-1$ vs. many $=+1$ ) and centered regulatory orientation were entered as predictors in Step 1; the interaction term was entered in Step 2. As expected, ease-of-retrieval was significantly lower after accessing many arguments_-which is difficult_compared

\footnotetext{
1 The instrument developed by Lockwood et al. (2002) has been criticized by Summerville and Roese (2008) as well as by Haws et al. (2010), who argue that the instrument's subscales are correlated with (affective) valence. This criticism can, however, be countered on theoretical and empirical grounds (Ineichen et al. 2010). Moreover, an alternative instrument to measure individual differences in regulatory foci-the Regulatory Focus Questionnaire (Higgins et al. 2001) - has not remained free of criticism either (cf. Halamish et al. 2008; Haws et al., 2010). Against this background, and to connect the present findings with earlier evidence collected with this instrument, we decided to use the instrument developed by Lockwood et al. (2002).
} 
to few arguments-which is easy-, as reflected in a main effect of experimental condition, $\beta=-.44, t(73)=$ $-4.23, p<.01$ (all other $|t| \mathrm{s}<1$ ).

\section{Hypothesis testing}

Evaluation of the airport extension was assessed as the primary dependent variable. Because the five items were highly interrelated (Cronbach's $\alpha=.94$ ), they were averaged and entered as the dependent variable in the hierarchical regression analysis described above. The analyses in Step 1 revealed a tendency for evaluation scores to be higher with increasing relative promotion orientation, $\beta=-.11, t(74)=-1.00, p>.32$, and a tendency for evaluation scores to be higher after few versus many arguments had been accessed, $\beta=-.11, t(74)=-0.95$, $p>.34$. Both tendencies were qualified by the hypothesized significant interaction of number of arguments and regulatory orientation, $\beta=.23, t(73)=2.03, p<.05$, $\Delta R^{2}=.05$ (see Fig. 1). To further explore this finding, we analyzed simple slopes following suggestions by Aiken and West (1991). For relative promotion orientation-one standard deviation below the mean-evaluation was more positive after recalling few as compared to many arguments, $\beta=-.34, t(73)=-2.12, p<.04$. In line with earlier research (Schwarz et al. 1991), we interpret this pattern as evidence of reliance on ease-of-retrieval in judgment. ${ }^{2}$ At the mean value, evaluations were-nonsignificantly-more positive after recalling few versus many arguments, $\beta=-.11,|t|<.97$, thus reflecting, if any, a mild tendency to rely on ease-of-retrieval. In contrast, for relative prevention orientation-one standard deviation above the mean-there was a non-significant tendency for evaluation scores to be more positive after recalling many as compared to few arguments, $\beta=.12$, $t<1$. This suggests that prevention orientation fosters reliance on content rather than reliance on ease-of-retrieval in judgment.

\footnotetext{
${ }^{2}$ In the ease-of-retrieval task, more positive evaluations after few as compared with many positive arguments have been recalled is interpreted as reliance on ease-of-retrieval (Schwarz et al. 1991; for reviews, Schwarz 1998, 2004). Alternatively, however, it has been speculated that findings such as these reflect disguised content effects. This argument holds that instances coming to mind later could potentially be less persuasive or of worse quality than those coming to mind earlier, such that the overall persuasiveness or quality of instances would be different in the few-condition versus in the manycondition. Extant literature has addressed these objections with a diverse set of methods (e.g., Ruder and Bless 2003; Schwarz et al. 1991; Wänke et al. 1996). It would therefore seem that the ease-ofretrieval paradigm allows for drawing inferences about reliance on ease-of-retrieval with reasonable confidence.
}

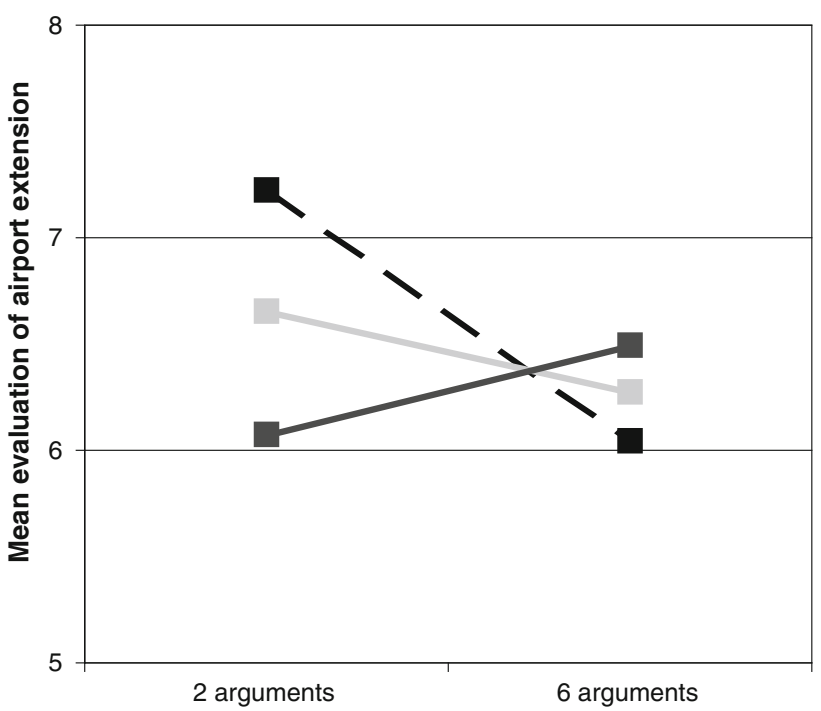

Fig. 1 Mean evaluation scores as a function of the number of arguments (2 vs. 6) and predominant habitual regulatory orientation (promotion $=$ dotted black line $/$ no predominance $=$ grey line $/$ prevention = black line $)$ in Experiment 1 . Higher values indicate more positive evaluation on a scale from 1 to 9

\section{Discussion}

Experiment 1 was conducted to offer first evidence that regulatory orientation moderates reliance on ease-ofretrieval versus content in judgment. To this end, we relied on the ease-of-retrieval task introduced by Schwarz et al. (1991) and assessed regulatory orientation as a dispositional measure (Lockwood et al. 2002). We observed a significant moderation in that promotion orientation was associated with reliance on ease-of-retrieval, whereas prevention orientation was not. Note that the non-significant result for relatively prevention-oriented participants should be considered in light of the fact that previous research has documented a fairly strong overall tendency for participants to rely on ease-of-retrieval (e.g., Schwarz et al. 1991). Given this earlier evidence, it is noteworthy that a substantial impact of habitual self-regulatory orientation could be documented as reflected in the fact that reliance on ease-of-retrieval disappears in relatively preventionoriented participants. Note also that, from a statistical perspective, the observed disordinal pattern of results suggests that a significant content effect might be observed at more extreme levels of relative prevention orientation.

\section{Experiment 2}

Experiment 1 provided first evidence that regulatory focus orientation moderates reliance on ease-of-retrieval versus content in judgment. To strengthen the empirical basis for this hypothesis, we conducted a second experiment designed 
to replicate Experiment 1 with a different measure of habitual regulatory focus orientation. If different measures converge in parallel findings, we can be more confident that reliance on ease-of-retrieval in judgment is particularly pronounced among individuals characterized as predominantly promotion-oriented versus prevention-oriented.

\section{Method}

\section{Participants and design}

A total of 60 University of Mannheim students participated in return for 1 EUR and a chocolate bar (total about 1.70 USD at that time) in a study on "information processing." Participants were randomly assigned to one of two conditions accessing either 2 (few) or 6 (many) arguments. Three participants were excluded from further analyses because they had already participated in an earlier ease-of-retrieval experiment. Of the remaining participants, 34 were female, 23 were male, and the mean age was 22.75 years $(\mathrm{SD}=3.54)$.

\section{Procedure and materials}

Procedure and materials were identical to those of Experiment 1 except for the following important modification: Instead of assessing habitual regulatory orientation with the measure developed by Lockwood et al. (2002), we employed a ten item short version of the Regulatory Concerns Questionnaire (Keller 2008). This instrument, which has been validated in a series of studies (Ineichen et al. 2010; Keller 2008; Keller and Bless 2008), includes questions referring to the likelihood of experiencing promotion- versus prevention-specific emotions as well as questions referring to the motivating strength of promotion- versus prevention-related contexts. All items are provided in the Appendix. Items were scaled from 1, does not apply, to 9, strongly applies. As in Experiment 1, relative focus orientation was computed by separately averaging promotion items (Cronbach's $\alpha=.76$ ) and prevention items (Cronbach's $\alpha=.75$ ), and then subtracting the promotion from the prevention average (overall $M=-1.12, \mathrm{SD}=1.87$ ).

Results and discussion

\section{Preliminary analyses}

As in Experiment 1, we assessed regulatory focus orientation at the end of the experiment so as to prevent heightened salience of regulatory concerns. Although methodologically preferable, this procedure requires testing whether the independent variable, number of arguments, differentially affected the assessment of the continuous moderator, regulatory orientation. To address this concern, regulatory orientation was submitted to a t-test for independent groups (few vs. many arguments). Because this analysis yielded no meaningful difference, $t(55)=1.24, p>.22$, we conclude that the assessment of dispositional regulatory orientation was unaffected by the situational manipulation of ease-of-retrieval.

To test for the success of the ease-of-retrieval manipulation, the three items targeting perceived ease or difficulty were averaged (Cronbach's $\alpha=.87$ ) and entered as dependent variable in a hierarchical regression analysis. Number of arguments (few $=-1$ vs. many $=+1$ ) and centered regulatory orientation were entered as predictors in Step 1; the interaction term was entered in Step 2. As expected, a main effect of number of arguments reflects that ease-of-retrieval was significantly lower after accessing many arguments, which is difficult, as compared to few arguments, which is easy, $\beta=-.63, t(54)=-5.93$, $p<.01$. Unexpectedly, we observed (a) a non-significant main effect of regulatory orientation, which reflects the tendency for ease-of-retrieval to be lower the more individuals were prevention-focused, $\beta=-.19, \quad t(54)=$ $-1.80, p<.10$, and (b) that both main effects were qualified by the interaction term in Step $2, \beta=.24, t(53)=$ $-2.38, p<.03$. However, further analysis of simple slopes following suggestions by Aiken and West (1991) revealed that ease-of-retrieval was higher after recalling few versus many arguments at all three levels of the moderator (one standard deviation below the mean, the mean, and one standard deviation above the mean), all $\beta \mathrm{s}<-.38$, $t \mathrm{~s}(53)<-2.65, p \mathrm{~s}<.02$. This suggests that all participants experienced ease-of-retrieval, though the experience was strongest for relative promotion orientation, and least strong-but still significant-for relative prevention orientation. Because ease-of-retrieval was experienced at all levels, the observed interaction seems unfortunate but does not limit the interpretability of the results reported below.

\section{Hypothesis testing}

Evaluation of the airport extension was assessed as the primary dependent variable. Because the five items were highly interrelated (Cronbach's $\alpha=.96$ ), they were averaged and entered as dependent variable in the described hierarchical regression analysis. Analyses in Step 1 revealed a non-significant tendency for evaluation scores to be higher after few as compared with many arguments had been recalled, $\beta=$ $-.18, t(54)=-1.29, p<.21$, reflecting an overall tendency for ease-of-retrieval (main effect regulatory orientation, $t<1$ ). Analyses in Step 2 additionally revealed the hypothesized significant interaction of number of arguments and regulatory orientation, $\beta=.29, t(53)=2.25, p<.05$, $\Delta R^{2}=.08$ (see Fig. 2). To further explore this finding, we 


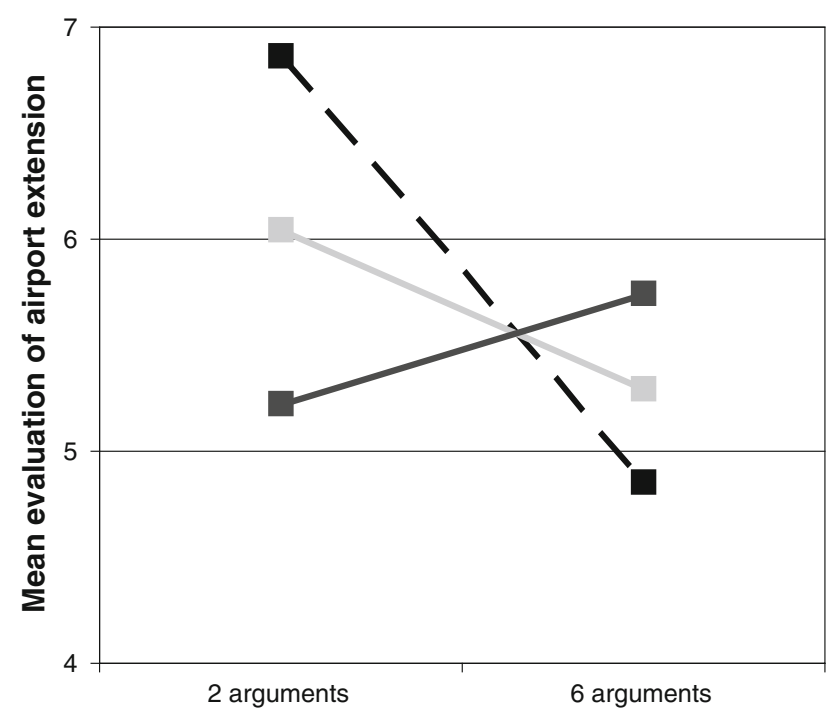

Fig. 2 Mean evaluation scores as a function of the number of arguments (2 vs. 6) and predominant habitual regulatory orientation (promotion $=$ dotted black line $/$ no predominance $=$ grey line/prevention $=$ black line $)$ in Experiment 2 . Higher values indicate more positive evaluation on a scale from 1 to 9

analyzed simple slopes following suggestions by Aiken and West (1991). For relative promotion orientation—one standard deviation below the mean-evaluation scores were more positive after recalling few as compared with many arguments, $\beta=-.47, t(53)=-2.54, p<.02$. In line with conclusions drawn in earlier research (Schwarz et al. 1991), this pattern of results suggests that participants relied on ease-of-retrieval in judgment. At the mean value, evaluations were non-significantly more positive after recalling few versus many arguments, $\beta=-.17, t(53)=-1.34, p<.19$. In contrast, for relative prevention orientation-one standard deviation above the mean-there was a non-significant tendency for evaluation scores to be more positive after recalling many as compared with few arguments, $\beta=.12$, $t<1$, suggesting that prevention orientation was not associated with reliance on ease-of-retrieval in judgment.

To summarize, Experiment 2 replicated the findings observed in Experiment 1 and supports the hypothesis that reliance on ease-of-retrieval in judgment is more likely to emerge in individuals characterized as predominantly promotion- versus prevention-oriented. Because the two experiments employed different measures of habitual regulatory orientation, the results attest to the reliability of the pattern and conclusions can be drawn with reasonable levels of confidence.

\section{General discussion}

Differences in self-regulation-both situationally induced and habitually available - have been found to strongly determine cognition and behavior (see contributions in Baumeister and Vohs 2004). In recognition of this important role, the current contribution investigated whether an eager form of self-regulation known as promotion focus, as compared with a cautious or vigilant form of self-regulation known as prevention focus, differentially affects reliance on two distinct sources of information in judgment: accessible content versus ease-of-retrieval experiences. In particular, we hypothesized that reliance on ease-ofretrieval is particularly pronounced among individuals characterized as predominantly promotion-oriented compared to those characterized as predominantly preventionoriented. In support of this hypothesis, two experiments that manipulated ease-of-retrieval and assessed habitual regulatory orientation found a significant moderating role of self-regulatory orientation in the predicted direction.

At least two aspects of this finding deserve short mention. First, the two experiments yielded very similar findings despite the fact that two distinct measures of habitual regulatory orientation were used (Experiment 1: Lockwood et al. 2002; Experiment 2: Keller 2008). That two different measures of habitual self-regulation tendencies produce parallel patterns of findings attests to the general nature of the observed moderation effect.

Second, in both experiments, the hypothesized interaction effect and a simple effect of ease-of-retrieval for predominant promotion orientation were obtained. Both experiments, however, also revealed that the simple effect of reliance on content for predominant prevention orientation did not reach conventional levels of significance. Although statistically secondary against the background of the robust interaction effect, this non-significant reversal of the effect is noteworthy. Perhaps most importantly, this non-significant content effect allows for connecting the current findings to earlier research that found overall easeof-retrieval effects without investigating self-regulatory orientation (Schwarz et al. 1991). This is because, across all participants, the ease-of-retrieval effect for those classified as promotion-oriented and the non-significant content effect for those classified as prevention-oriented combine to an overall, though non-significant, ease-of-retrieval main effect (see Steps 1 in both regression analyses). When compared with earlier research that has documented significant ease-of-retrieval main effects, our studies showed only a tendency, presumably because the materials and topic (extension of the local city airport) may have encouraged a focus on the content of the retrieved information, thus loading the dice against an overall ease-ofretrieval effect (e.g., Florack and Zoabi 2003).

Going beyond the observed evidence, the current findings allow for several important implications. First, they add to the regulatory focus literature by documenting specific judgment characteristics of promotion-oriented versus 
prevention-oriented self-regulation. In particular, these results provide the first available evidence documenting that promotion is associated with reliance on ease-of-retrieval, whereas prevention is not. This finding extends a growing body of research that addresses the reliance on distinct information sources in judgment for the two self-regulatory orientations of promotion versus prevention (e.g., Florack et al. 2010; Pham and Avnet 2004). Given the fundamental nature and implications of these motivational orientations, and given that habitual differences between individuals can be observed, it is critical to understand how self-regulation orientation shapes judgment and decision making. These findings add an important piece to this picture. At the same time, they also outline a path for future research, which, for instance, may fruitfully explore which specific aspects of self-regulation in promotion and prevention trigger differential selection of information sources.

Second, these findings add to the literature on metacognition by identifying self-regulation as a moderator of the reliance on ease-of-retrieval in judgment. The investigation of moderating variables is critical because it allows for the specification of the conditions in which an effect is likely to occur and thus for gauging an effect's prevalence outside scientific laboratories (Zanna and Fazio 1982). Because there seems to be a slight dominance of promotion over prevention focused self-regulation in habitual tendencies (in Western societies, cf. Lee et al. 2000; Uskul et al. 2009), the present findings may be interpreted in line with earlier conclusions that suggest that reliance on easeof-retrieval may be the rule rather than the exception (e.g., Schwarz et al. 2008).

But why does self-regulatory orientation act as a moderator? The effect of regulatory orientation seems best characterized as reflecting what Greifeneder et al. (2011a) coined the "relevance principle," which holds that feelings may or may not be used in judgment depending on whether the feelings are perceived to be relevant for the specific judgment. Promotion-focused and prevention-focused regulatory tendencies can be presumed to recruit different information sources because of their apparent compatibility with, or relevance to, current regulatory concerns. Given that, the current findings increase our understanding of how the use of different information sources is channeled. Moreover, together with a host of other findings, our findings regarding moderation allow for the conclusion that the use of feelings versus content in judgment is a finely tuned process that takes a number of factors into account.

The explanation outlined above focuses on the compatibility of accessible content versus accessibility experiences with the primary exploration and processing strategies of prevention- versus promotion-focused regulation. Alternatively, one may argue that promotion-focused individuals experienced a "feeling right" when listing arguments in favor of the airport extension, whereas prevention-focused individuals did not. This regulatory fit may have invited the consideration of information sources that are particularly easy to access, such as ease-of-retrieval experiences, while its absence could have spurred careful scrutiny of the available content information (for a review on regulatory fit, e.g., Higgins 2006). The present data do not allow for disentangling these alternative explanations. However, future research may test the explanations against each other by asking participants to recall either arguments in favor of or arguments against the airport extension. The compatibility account would suggest that changes in argument valence should not alter the general pattern of results. In contrast, the regulatory fit account would assume that with arguments against the airport extension, prevention-oriented individuals should display a preference for reliance on ease-ofretrieval in judgment.

Before concluding, we wish to acknowledge that the experiments in this paper did not include a situational manipulation of regulatory focus. Although experimental data is generally desirable, it would appear that converging evidence with two distinct dispositional measures is a solid basis for conclusions, as well, and perhaps the basis that allows for a broader set of conclusions beyond the specifics of the reported experiments. Nevertheless, future research may fruitfully extend the present findings by situationally manipulating regulatory focus orientation.

In summary, the current findings can be viewed as a contribution to the understanding of the role self-regulatory mechanisms play in judgment and decision making, and they enrich our knowledge about the factors that affect individuals' tendency to rely on distinct sources of information. As such, the current studies contribute to ongoing research endeavors studying metacognitive processes and highlight the crucial impact of self-regulatory mechanisms. For researchers specifically interested in self-regulation, the work presented seems valuable in that we document specific judgment processes as correlates of basic selfregulatory orientations.

Acknowledgments This research was supported by a post-doctoral grant from the Deutsche Forschungsgemeinschaft awarded to the first author.

\section{Appendix: Regulatory Concerns Questionnaire}

10-item short-version of the Regulatory Concerns Questionnaire (Keller 2008). Items were scaled from 1, does not apply, to 9, strongly applies. Promotion-Items: 1, 3, 7, 8, 10; Prevention-Items: 2, 4, 5, 6, 9.

1. Imagine that you are participating in an application process (Assessment Center) in a company. How strong would your ambition be to make the most 
positive impression possible in this application process?

2. If I do not reach a goal I have set for myself, I am perturbed and brood on my mistakes.

3. In situations in which my performance is being judged, I often feel the desire to do well.

4. When I am confronted with negative expectations about my ability, I feel pressured and tense.

5. Imagine you are participating in an application process (Assessment Center) at a company. How strong would be your fear of embarrassing yourself in this process?

6. In situations in which my performance is being judged, I often feel tense and unwell.

7. If I know that my performance is being evaluated by other people, that spurs me on and increases my ambition to do well.

8. If other people express doubts about my ability to perform, I am especially motivated to refute these doubts and do very well.

9. My life is often shaped by fear of failure and negative events.

10. I hope that in my future professional life, I will be given great challenges that awaken my ambition.

\section{References}

Aarts, H., \& Dijksterhuis, A. (1999). How often did I do it? Experienced ease of retrieval and frequency estimates of past behavior. Acta Psychologica, 103, 77-89. doi:10.1016/S00016918(99)00035-9.

Aiken, L. S., \& West, S. G. (1991). Multiple regression: Testing and interpreting interactions. Newbury Park, CA: Sage.

Alter, A. L., \& Oppenheimer, D. M. (2009). Uniting the tribes of fluency to form a metacognitive nation. Personality and Social Psychology Review, 13, 219-235. doi:10.1177/10888683093 41564.

Baumeister, R., \& Vohs, K. D. (2004). Handbook of self-regulation: Research, theory, and application. New York, NY: Guilford Press.

Cesario, J., Grant, H., \& Higgins, E. T. (2004). Regulatory fit and persuasion: Transfer from 'feeling right'. Journal of Personality and Social Psychology, 86, 388-404. doi:10.1037/0022-3514. 86.3.388.

Clore, G. L. (1992). Cognitive phenomenology: Feelings and the construction of judgment. In L. L. Martin \& A. Tesser (Eds.), The construction of social judgments (pp. 133-163). Hillsdale, NJ: Erlbaum.

Clore, G. L., Gasper, K., \& Garvin, E. (2001). Affect as information. In J. P. Forgas (Ed.), Handbook of affect and social cognition (pp. 121-144). Mahwah, NJ: Erlbaum.

Dijksterhuis, A., Macrae, C. N., \& Haddock, G. (1999). When recollective experiences matter: Subjective ease of retrieval and stereotyping. Personality and Social Psychology Bulletin, 25, 760-768. doi:10.1177/0146167299025006010.

Elster, J. (1999). Alchemies of the mind: Rationality and the emotions. Cambridge: Cambridge University Press.

Evans, L. M., \& Petty, R. E. (2003). Self-guide framing and persuasion: Responsibly increasing message processing to ideal levels. Personality and Social Psychology Bulletin, 29, 313-324. doi:10.1177/0146167202250090.

Florack, A., Friese, M., \& Scarabis, M. (2010). Regulatory focus and reliance on implicit preferences in consumption contexts. Journal of Consumer Psychology, 20, 193-204. doi:10.1016/j. jcps.2010.02.001.

Florack, A., \& Zoabi, H. (2003). Risikoverhalten bei Aktiengeschäften: Wenn Anleger nachdenklich werden (Risk behavior in share transactions: When investors think about reasons). Zeitschrift für Sozialpsychologie, 34, 65-78. doi:10.1024//0044-3514.34.2.65.

Förster, J., \& Higgins, E. T. (2005). How global versus local perception fits regulatory focus. Psychological Science, 16, 631-636. doi:10.1111/j.1467-9280.2005.01586.x.

Förster, J., Higgins, E. T., \& Bianco, A. T. (2003). Speed/accuracy decisions in task performance: Built-in trade-off or separate strategic concerns? Organizational Behavior and Human Decision Processes, 90, 148-164. doi:10.1016/S0749-5978(02) 00509-5.

Friedman, R. S., \& Förster, J. (2000). The effects of approach and avoidance motor actions on the elements of creative insight. Journal of Personality and Social Psychology, 79, 477-492. doi: 10.1037/0022-3514.79.4.477.

Friedman, R. S., \& Förster, J. (2001). The effects of promotion and prevention cues on creativity. Journal of Personality and Social Psychology, 81, 1001-1013. doi:10.1037/0022-3514.81.6.1001.

Greifeneder, R., \& Bless, H. (2007). Relying on accessible content versus accessibility experiences: The case of processing capacity. Social Cognition, 25, 853-881. doi:10.1521/soco.2007.25.6.853.

Greifeneder, R., \& Bless, H. (2008). Depression and reliance on easeof-retrieval experiences. European Journal of Social Psychology, 38, 213-230. doi:10.1002/ejsp.451.

Greifeneder, R., Bless, H., \& Pham, M. T. (2011a). When do people rely on affective and cognitive feelings in judgment? A review. Personality and Social Psychology Review, 15, 107-141. doi: 10.1177/1088868310367640.

Greifeneder, R., Müller, P., Stahlberg, D., Van den Bos, K., \& Bless, H. (2011b). Beyond procedure's content: Cognitive subjective experiences in procedural justice judgments. Experimental Psychology, 58, 341-352. doi:10.1027/1618-3169/a000101.

Haddock, G. (2002). It's easy to like or dislike Tony Blair: Accessibility experiences and the favourability of attitude judgments. British Journal of Psychology, 93, 257-267. doi: 10.1348/000712602162571.

Haddock, G., Rothman, A. J., Reber, R., \& Schwarz, N. (1999). Forming judgments of attitude certainty, intensity, and importance: The role of subjective experiences. Personality and Social Psychology Bulletin, 25, 771-782. doi:10.1177/014616729 9025007001.

Halamish, V., Liberman, N., Higgins, E. T., \& Idson, L. C. (2008). Regulatory focus effects on discounting over uncertainty for losses vs. gains. Journal of Economic Psychology, 29, 654-666. doi:10.1016/j.joep.2007.09.002.

Haws, K. L., Dholakia, U. M., \& Bearden, W. O. (2010). An assessment of chronic regulatory focus measures. Journal of Marketing Research, 47, 967-982. doi:10.1509/jmkr.47.5.967.

Higgins, E. T. (1997). Beyond pleasure and pain. American Psychologist, 52, 1280-1300. doi:10.1037/0003-066X.52.12.1280.

Higgins, E. T. (1998). Promotion and prevention: Regulatory focus as a motivational principle. In M. P. Zanna (Ed.), Advances in experimental social psychology (Vol. 30, pp. 1-46). San Diego, CA: Academic Press.

Higgins, E. T. (2006). Value from hedonic experience and engagement. Psychological Review, 113, 439-460. doi:10.1037/0033295X.113.3.439.

Higgins, E. T., Friedman, R. S., Harlow, R. E., Idson, L. C., Ayduk, O. N., \& Taylor, A. (2001). Achievement orientations from 
subjective histories of success: Promotion pride versus prevention pride. European Journal of Social Psychology, 31, 3-23. doi:10.1002/ejsp.27.

Higgins, E. T., \& Spiegel, S. (2004). Promotion and prevention strategies for self-regulation: A motivated cognition perspective. In R. F. Baumeister \& K. D. Vohs (Eds.), Handbook of selfregulation: Research, theory, and applications (pp. 171-187). New York, NY: Guilford Press.

Ineichen, S., Florack, A., Keller, J., Leder, S., \& Lockwood, P. (2010). How to measure general regulatory focus: Validation of a self-report measure. Unpublished manuscript, University of Ulm.

Janssen, J., Müller, P., \& Greifeneder, R. (2011). Cognitive processes in procedural justice judgments. The role of ease-of-retrieval, uncertainty, and experience. Journal of Organizational Behavior, 32, 726-750. doi:10.1002/job.700.

Keller, J. (2008). Development and validation of a self-report scale assessing performance-related chronic self-regulatory concerns: The regulatory concerns questionnaire. Unpublished manuscript, University of Ulm, Germany.

Keller, J., \& Bless, H. (2008). When positive and negative expectancies disrupt performance: Regulatory focus as a catalyst. European Journal of Social Psychology, 38, 187-212. doi: 10.1002/ejsp.452.

Koriat, A., \& Levy-Sadot, R. (1999). Processes underlying metacognitive judgments: Information-based and experience-based monitoring of one's own knowledge. In S. Chaiken \& Y. Trope (Eds.), Dual-process theories in social psychology (pp. 483-502). New York, NY: Guilford Press.

Lee, A. Y., \& Aaker, J. L. (2004). Bringing the frame into focus: The influence of regulatory fit on processing fluency and persuasion. Journal of Personality and Social Psychology, 86, 205-218. doi: 10.1037/0022-3514.86.2.205.

Lee, A. Y., Aaker, J. L., \& Gardner, W. L. (2000). The pleasures and pains of distinct self-construals: The role of interdependence in regulatory focus. Journal of Personality and Social Psychology, 78, 1122-1134. doi:10.1037/0022-3514.78.6.1122.

Liberman, N., Idson, L. C., Camacho, C. J., \& Higgins, E. T. (1999). Promotion and prevention choices between stability and change. Journal of Personality and Social Psychology, 77, 1135-1145. doi:10.1037/0022-3514.77.6.1135.

Lockwood, P., Jordan, C. H., \& Kunda, Z. (2002). Motivation by positive or negative role models: Regulatory focus determines who will best inspire us. Journal of Personality and Social Psychology, 83, 854-864. doi:10.1037/0022-3514.83.4.854.

Molden, D. C., \& Higgins, E. T. (2008). How preferences for eager versus vigilant judgment strategies affect self-serving conclusions. Journal of Experimental Social Psychology, 44, 1219-1228. doi:10.1016/j.jesp.2008.03.009.

Molden, D. C., Lee, A. Y., \& Higgins, E. T. (2008). Motivations for promotion and prevention. In J. Y. Shah \& W. L. Gardner (Eds.), Handbook of motivation science (pp. 169-187). New York, NY: Guilford Press.

Pham, M. T., \& Avnet, T. (2004). Ideals and oughts and the reliance on affect versus substance in persuasion. Journal of Consumer Research, 30, 503-518. doi:10.1086/380285.
Pham, M. T., \& Avnet, T. (2009). Contingent reliance on the affect heuristic as a function of regulatory focus. Organizational Behavior and Human Decision Processes, 108, 267-278. doi: 10.1016/j.obhdp.2008.10.001.

Ruder, M., \& Bless, H. (2003). Mood and the reliance on the ease of retrieval heuristic. Journal of Personality and Social Psychology, 85, 20-32. doi:10.1037/0022-3514.85.1.20.

Schwarz, N. (1998). Accessible content and accessibility experiences: The interplay of declarative and experiential information in judgment. Personality and Social Psychology Review, 2, 87-99. doi:10.1207/s15327957pspr0202_2.

Schwarz, N. (2004). Metacognitive experiences in consumer judgment and decision making. Journal of Consumer Psychology, 14, 332-348. doi:10.1207/s15327663jcp1404_2.

Schwarz, N., Bless, H., Strack, F., Klumpp, G., Rittenauer-Schatka, H., \& Simons, A. (1991). Ease of retrieval as information: Another look at the availability heuristic. Journal of Personality and Social Psychology, 61, 195-202. doi:10.1037/0022-3514. 61.2.195.

Schwarz, N., \& Clore, G. L. (2007). Feelings and phenomenal experiences. In E. T. Higgins \& A. W. Kruglanski (Eds.), Social psychology: Handbook of basic principles (2nd ed., pp. 385407). New York, NY: Guilford Press.

Schwarz, N., Song, H., \& Xu, J. (2008). When thinking is difficult: Metacognitive experiences as information. In M. Wänke (Ed.), Social psychology of consumer behavior (pp. 201-223). New York: Psychology Press.

Summerville, A., \& Roese, N. J. (2008). Self-report measures of individual differences in regulatory focus: A cautionary note. Journal of Research in Personality, 42, 247-254. doi: 10.1016/j.jrp.2007.05.005.

Tversky, A., \& Kahneman, D. (1973). Availability: A heuristic for judging frequency and probability. Cognitive Psychology, 5, 207-232. doi:10.1016/0010-0285(73)90033-9.

Uskul, A. K., Sherman, D. K., \& Fitzgibbon, J. (2009). The cultural congruency effect: Culture, regulatory focus, and the effectiveness of gain- vs. loss-framed health messages. Journal of Experimental Social Psychology, 45, 535-541. doi:10.1016/j. jesp.2008.12.005.

Wänke, M., Bless, H., \& Biller, B. (1996). Subjective experience versus content of information in the construction of attitude judgments. Personality and Social Psychology Bulletin, 22, 1105-1113. doi:10.1177/01461672962211002.

Wänke, M., Bohner, G., \& Jurkowitsch, A. (1997). There are many reasons to drive a BMW: Does imagined ease of argument generation influence attitudes? Journal of Consumer Research, 24, 170-177. doi:10.1086/209502.

Winkielman, P., Schwarz, N., \& Belli, R. F. (1998). The role of ease of retrieval and attribution in memory judgements: Judging your memory as worse despite recalling more events. Psychological Science, 9, 124. doi:10.1111/1467-9280.00022.

Zanna, M. P., \& Fazio, R. H. (1982). The attitude-behavior relation: Moving toward a third generation of research. In M. P. Zanna, E. T. Higgins, \& C. P. Herman (Eds.), Consistency in social behavior. The Ontario symposium on personality and social psychology (Vol. 2, pp. 283-301). Hillsdale, NJ: Erlbaum. 